\title{
Comparative proteomic analysis of the contractile-protein-depleted fraction from normal versus dystrophic skeletal muscle
}

\author{
Steven Carberry ${ }^{\mathrm{a}}$, Margit Zweyer ${ }^{\mathrm{b}}$, Dieter Swandulla ${ }^{\mathrm{b}}$, Kay Ohlendieck ${ }^{\mathrm{a}, *}$ \\ ${ }^{a}$ Department of Biology, National University of Ireland, Maynooth, Kildare, Ireland \\ ${ }^{\mathrm{b}}$ Department of Physiology II, University of Bonn, D-53115 Bonn, Germany
}

\section{A R T I C L E I N F O}

\section{Article history:}

Received 7 June 2013

Received in revised form 3 August 2013

Accepted 6 August 2013

Available online 14 August 2013

\section{Keywords:}

Dystrophinopathy

Ferritin

Hsp70

Muscle proteomics

Transferrin

\begin{abstract}
A B S T R A C T
In basic and applied myology, gel-based proteomics is routinely used for studying global changes in the protein constellation of contractile fibers during myogenesis, physiological adaptations, neuromuscular degeneration, and the natural aging process. Since the main proteins of the actomyosin apparatus and its auxiliary sarcomeric components often negate weak signals from minor muscle proteins during proteomic investigations, we have here evaluated whether a simple prefractionation step can be employed to eliminate certain aspects of this analytical obstacle. To remove a large portion of highly abundant contractile proteins from skeletal muscle homogenates without the usage of major manipulative steps, differential centrifugation was used to decisively reduce the sample complexity of crude muscle tissue extracts. The resulting protein fraction was separated by two-dimensional gel electrophoresis, and 2Dlandmark proteins were identified by mass spectrometry. To evaluate the suitability of the contractileprotein-depleted fraction for comparative proteomics, normal versus dystrophic muscle preparations were examined. The mass spectrometric analysis of differentially expressed proteins, as determined by fluorescence difference in-gel electrophoresis, identified 10 protein species in dystrophic $m d x$ hindlimb muscles. Interesting new biomarker candidates included Hsp70, transferrin, and ferritin, whereby their altered concentration levels in dystrophin-deficient muscle were confirmed by immunoblotting.
\end{abstract}

(c) 2013 Elsevier Inc. All rights reserved.
In high-throughput biochemistry, mass spectrometry is the method of choice for the fast and reliable identification of proteins in large-scale surveys of physiological or pathological processes [1-3]. This makes protein mass spectrometry an integral part of biological network analysis [4] and the discovery of novel disease biomarker signatures [5]. Disorder-specific protein markers play a central diagnostic, prognostic, and therapeutic role in skeletal muscle pathology and the systematic application of proteomics has greatly expanded the range of biomarkers for neuromuscular disorders [6]. Proteome-wide studies combine protein separation methods, such as high-resolution two-dimensional gel electrophoresis [7-9] and liquid chromatography [10], with sophisticated mass spectrometric techniques to determine potential changes in protein concentration, isoform expression patterns, protein-protein interactions and posttranslational modifications [11-13].

However, proteomic findings from comparative studies focusing on total protein extracts from highly complex and dynamic types of tissues, such as skeletal muscle fibers, are often limited to mostly soluble and relatively abundant proteins [14-16], missing especially the classes of very low abundance proteins and

\footnotetext{
* Corresponding author. Fax: +3531708 3845 .

E-mail address: kay.ohlendieck@nuim.ie (K. Ohlendieck).
}

hydrophobic proteins. Thus, to cover all of the assessable constituents in a heterogeneous assembly of proteins with a greatly differing abundance and physicochemical properties, as are found in contractile tissues, organelle proteomics should be used to supplement the findings from whole tissue proteomics. The application of prefractionation procedures substantially reduces sample complexity and thus allows more comprehensive cataloging of complex muscle protein mixtures [17-20]. Muscle organelle proteomics has been successfully applied for studying fractions enriched in nuclei, mitochondria, surface membranes, the sarcoplasmic reticulum, the cytosol, and the contractile apparatus in normal, transforming, and pathological muscle [21].

Although the comprehensive analysis of low-copy number proteins in pathological samples is challenging, the proteomic identification of new protein disease markers promises a deeper understanding of pathophysiological mechanisms. To better comprehend the complex changes that occur during X-linked muscular dystrophy [22], we have analyzed here a contractile-protein-depleted fraction from normal versus dystrophic muscle preparations. Since extensive subcellular fractionation protocols may introduce artifacts, we have kept centrifugation steps to a minimum. Hence, the analytical strategy employed in this study is a compromise between using total extracts, which may result in 
the underrepresentation of minor muscle proteins, and extensive prefractionation protocols, which often complicate comparative studies by unintended entrapment, desorption, or clustering of certain proteins. Our study complements previous proteomic investigations into global changes in genetic animal models of Duchenne muscular dystrophy [23-27]. The proteomic analysis of the enriched protein fraction from normal versus dystrophic $m d x$ muscle has resulted in the identification of 10 novel protein species, including ferritin, transferrin, and various isoforms of the molecular chaperone Hsp70.

\section{Materials and methods}

\section{Materials}

For the gel electrophoretic separation of muscle proteins, materials and analytical grade chemicals, including CyDye DIGE fluor minimal dyes Cy3 and Cy5, were obtained from Amersham Biosciences/GE Healthcare (Little Chalfont, Buckinghamshire, UK). Digestion was performed with sequencing-grade-modified trypsin from Promega (Madison, WI, USA). Protease inhibitors and chemiluminescence substrate were purchased from Roche Diagnostics (Mannheim, Germany). Primary antibodies were from Abcam (Cambridge, UK; ab92721 to myosin light chain MLC2, ab6588 to collagen, ab11427 to parvalbumin, ab9033-1 to transferrin, and ab69090 to ferritin light chain), Sigma Chemical Co. (Dorset, UK; L-9393 to laminin), Enzo Stressgen (Victoria, BC, Canada; ADISPA-811 to heat shock protein Hsp70/72 rabbit), and Santa Cruz Biotechnology (Santa Cruz, CA, USA; sc-3370 to $\beta$-dystroglycan). Secondary antibodies were from Chemicon International (Temecula, CA, USA). All other chemicals used were of analytical grade and purchased from Sigma.

\section{Animal model of muscular dystrophy}

Dystrophin-deficient skeletal muscles from the naturally occurring mutant $m d x$ mouse model of Duchenne muscular dystrophy are widely used in proteomic screening studies [23]. Since this study employed a subcellular fractionation protocol prior to gel electrophoretic separation of the contractile-protein-depleted fraction and therefore required substantial amounts of starting material, the proteomic analysis was not carried out with a specific skeletal muscle, but combined muscles from the entire hindlimb. Dystrophic muscle from 8-week-old $m d x$ mice and normal control muscle from age-matched C57 mice were obtained from the Bioresource Unit of the University of Bonn [26]. Mice were kept under standard conditions and all procedures were performed in accordance with German guidelines on the use of animals for scientific experiments. Animals were sacrificed by cervical dislocation and muscle tissues quickly removed and quick-frozen in liquid nitrogen.

\section{Subcellular fractionation of skeletal muscle homogenates}

The subcellular fractionation of skeletal muscle tissue was based on previously optimized protocols for the separation of distinct functional elements from muscle homogenates [28,29]. Each pair of hindlimb muscles of approximately $0.65 \mathrm{~g}$ wet wt from $m d x$ and control mice was washed in ice-cold phosphate-buffered saline and cut into small pieces with a razor blade. Following suspension in $10 \mathrm{vol}$ of $20 \mathrm{mM}$ sodium pyrophosphate, $20 \mathrm{mM}$ sodium phosphate, $1 \mathrm{mM} \mathrm{MgCl}_{2}, 0.303 \mathrm{M}$ sucrose, $0.5 \mathrm{mM}$ EDTA, pH 7.0 [28], supplemented with a protease inhibitor cocktail [29], samples were treated with a hand-held homogenizer for $30 \mathrm{~s}$ every $10 \mathrm{~min}$ for $1 \mathrm{~h}$ at $4{ }^{\circ} \mathrm{C}$. Muscle homogenates were centrifuged at $14,000 \mathrm{~g}$ for $15 \mathrm{~min}$ and then the resulting supernatant was pelleted at $100,000 \mathrm{~g}$ for $1 \mathrm{~h}$ at $4{ }^{\circ} \mathrm{C}$. Microsomal pellets were resuspended in electrophoresis buffer and analyzed by gel-based proteomics. One preparation yielded approximately $0.8 \mathrm{mg}$ of microsomal protein.

\section{Gel electrophoretic analysis of muscle proteins}

Fluorescence two-dimensional (2D) gel electrophoretic analysis was carried out in the case of total tissue extracts by postelectrophoretic staining with ruthenium II tris bathophenanthroline disulfonate (RuBPs) [30] and for the comparative analysis of the contractile-protein-depleted fraction from normal versus dystrophic muscle by preelectrophoretic labeling using the difference in-gel electrophoresis (DIGE) method with CyDyes Cy3 and Cy5 [31]. Fluorescent RuBPs dye was prepared by the method of Aude-Garcia et al. [32]. First-dimension isoelectric focusing was performed with nonlinear $\mathrm{pH} 3-11$ strips and second-dimension slab-gel electrophoresis with $12.5 \%$ separating gels (gel size $24 \times 16 \mathrm{~cm}$ ). Our laboratory has optimized fluorescence labeling techniques for the analysis of skeletal muscle proteins. Detailed descriptions of the RuBPs-based analysis and the DIGE method as applied to muscle tissues have recently been published [33,34]. Total protein loading of RuBPs gels and DIGE gels was 600 and $100 \mu \mathrm{g}$ protein, respectively. Fluorescently labeled proteins were visualized with the help of a Typhoon Trio variable mode imager (Amersham Biosciences/GE Healthcare). Gel image analysis was carried out with Progenesis SameSpots software (Nonlinear Dynamics, Newcastle upon Tyne, UK). The following parameters were employed for the identification of significant differences in the concentration of proteins in the contractile-protein-depleted fraction from normal versus dystrophic muscle: ANOVA $p<0.05, n=4$, and a power value of $>0.8$. Proteins in $2 \mathrm{D}$ spots with a significant increase or decrease in abundance (differing between the various groups with $>1.4$-fold change) were subsequently identified by mass spectrometry.

\section{Mass spectrometric identification of muscle proteins}

Coomassie brilliant blue (CBB)-stained pick gels were used for the mass spectrometric identification of proteins of interest, as previously described in detail [35]. Total protein loading of CBB pick gels was $600 \mu \mathrm{g}$ protein. Following the excision, washing, and destaining of $2 \mathrm{D}$ spots, characteristic peptide populations were produced by treatment with sequencing-grade trypsin [31]. Peptide samples were dried through vacuum centrifugation and suspended in MS-grade distilled water and $0.1 \%$ formic acid, spun down through spin filters, and added to LC-MS vials for identification using a Model 6340 ion trap LC-MS apparatus from Agilent Technologies (Santa Clara, CA, USA). Conditions for the separation of peptide populations generated from individual muscle proteins and elution profiles were previously described in detail [30,31,33-35]. Database searches were carried out with Mascot MS/MS ion search (Matrix Science, London, UK; NCBI database, release 20100212). All searches employed "Mus musculus" as taxonomic category and the following parameters: (i) two missed cleavages by trypsin, (ii) mass tolerance of precursor ions $\pm 2 \mathrm{Da}$ and product ions $\pm 1 \mathrm{Da}$, (iii) carboxymethylated cysteines fixed modification, (iv) oxidation of methionine as variable modification, and ( $\mathrm{v}$ ) at least two matched distinct peptides. MS/MS scores over 40 are listed in Tables $1-3$.

\section{Immunoblot analysis of muscle proteins}

One-dimensional gel electrophoretic separation and immunoblotting were carried out by standard procedures [36] and used 


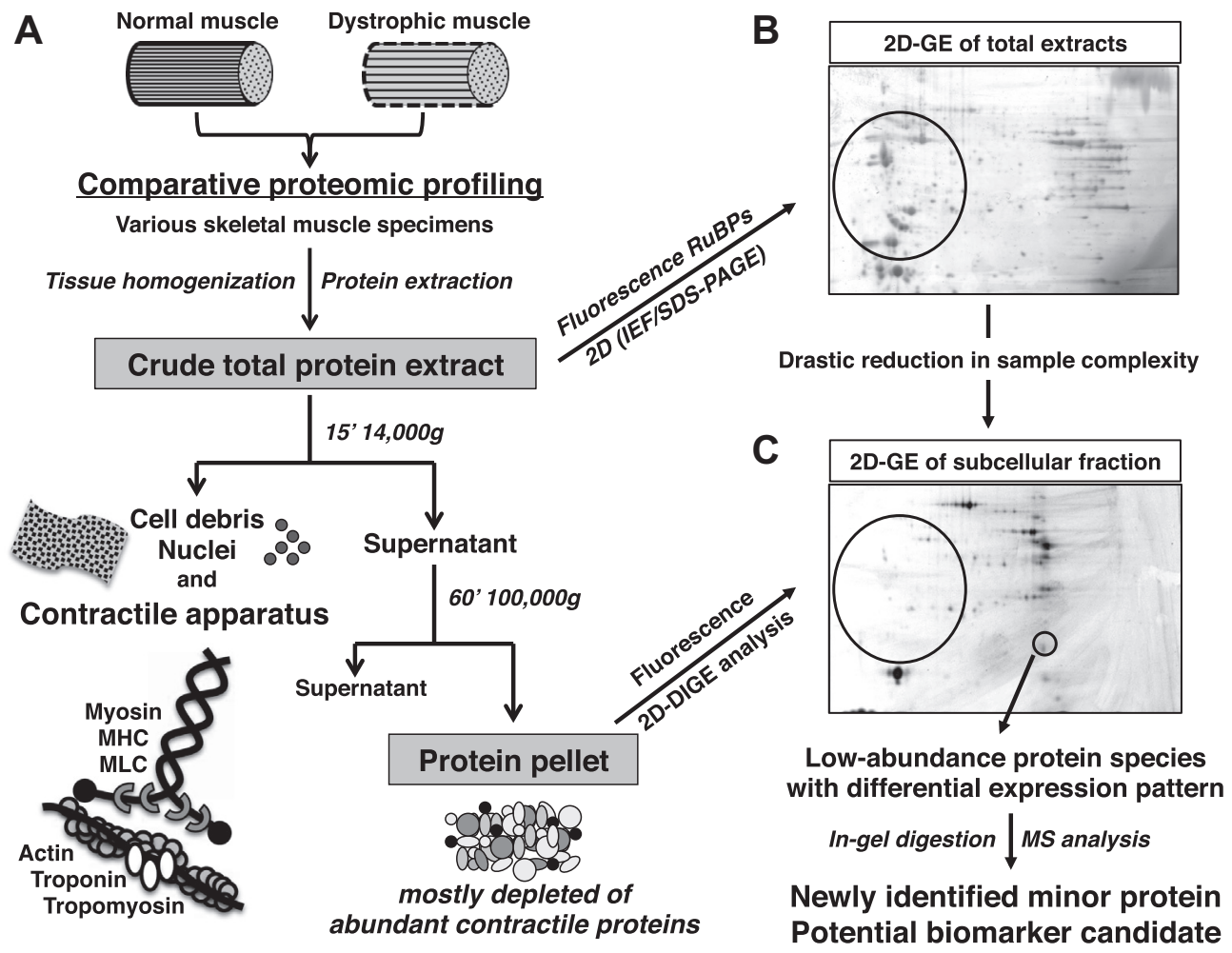

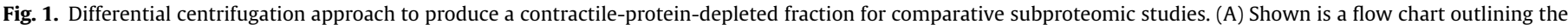

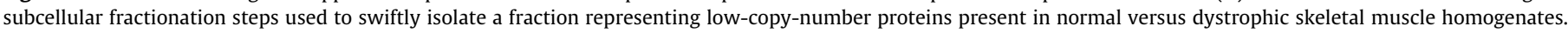

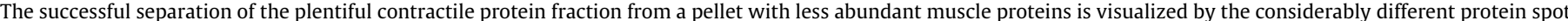

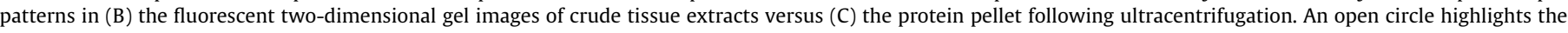
contractile protein-containing region of $2 \mathrm{D}$ gels in the acidic-to-neutral $\mathrm{pI}$ range.

to verify key findings from the comparative proteomic profiling of the contractile-protein-depleted fraction from normal versus dystrophic muscle. Using a Mini-Protean II electrophoresis and transfer system from Bio-Rad Laboratories (Hercules, CA, USA), muscle proteins were transferred to nitrocellulose for $70 \mathrm{~min}$ at $100 \mathrm{~V}$ and $4{ }^{\circ} \mathrm{C}$. A fat-free milk protein solution made up in phosphate-buffered saline was used to block membranes for $1 \mathrm{~h}$ [29]. Membrane sheets were then incubated with sufficiently diluted primary antibodies for $3 \mathrm{~h}$, washed several times, incubated for $1 \mathrm{~h}$ with secondary peroxidase-conjugated antibodies, and washed again, and then immuno-decorated bands were visualized with the chemiluminescence method. Densitometric scanning of

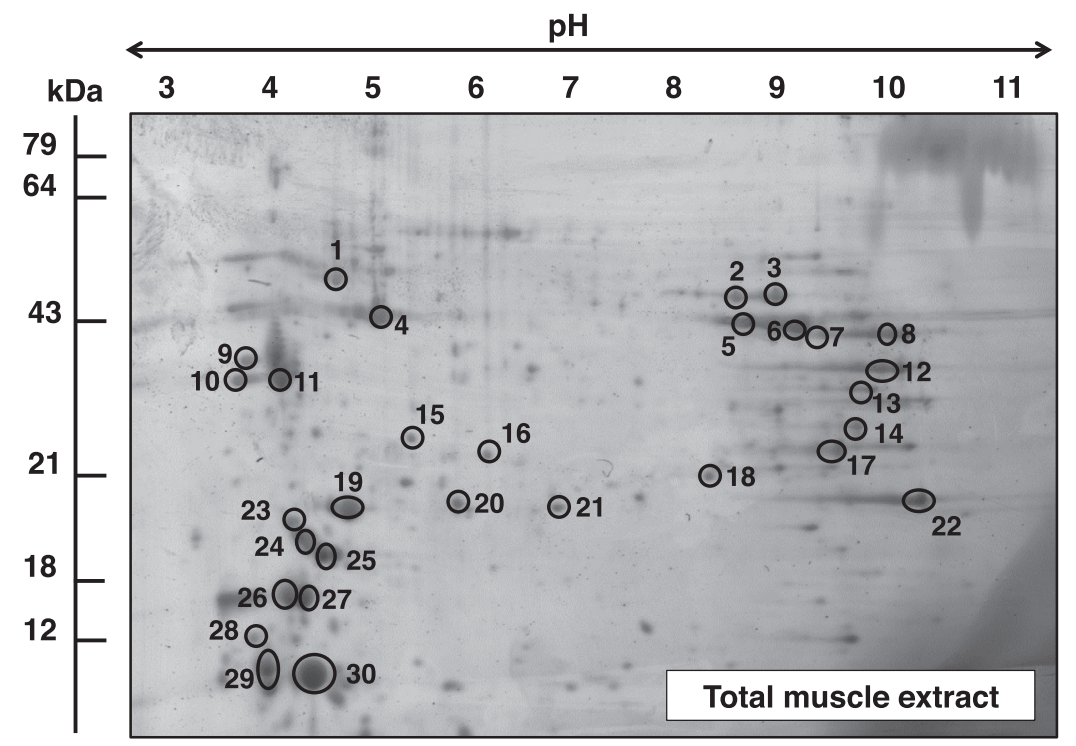

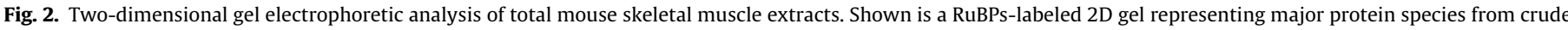

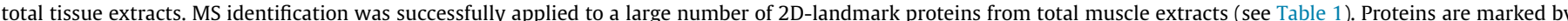

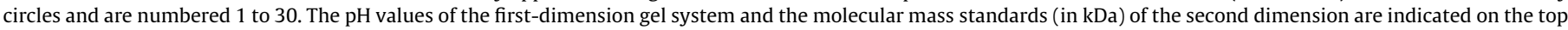
and on the left, respectively. 
immunoblots was performed using ImageJ (National Institutes of Health, Bethesda, MD, USA) software.

\section{Results}

\section{Differential centrifugation of muscle homogenates}

As outlined in Fig. 1, this study evaluated the suitability of a simple subcellular fractionation protocol for the swift removal of a large portion of the actomyosin apparatus from muscle homogenates to enable the comparative analysis of low-copy-number proteins by gel-based subproteomics. The separation of the plentiful contractile protein fraction from a microsomal pellet representing less abundant muscle proteins, as diagrammatically shown in the flow chart of Fig. 1A, is substantiated by the clearly different protein expression patterns in the fluorescent two-dimensional gel images. The drastic decrease in protein spots in the acidic-toneutral region on the left side of the gel image in Fig. 1C, compared to the crude extract depicted in Fig. 1B, indicates the successful removal of a considerable part of contractile elements, such as myosins, actins, troponins, and tropomyosins [16,29]. To verify the depletion of the actomyosin apparatus, mass spectrometry was employed to unequivocally identify abundant landmark protein spots within two-dimensional gels before and after differential centrifugation.

\section{Gel electrophoretic assessment of the contractile-protein-depleted fraction}

Following the gel electrophoretic separation and densitometric analysis of proteins present in crude muscle extracts (Fig. 2) and the contractile-protein-depleted subcellular fraction (Fig. 3), the mass spectrometric identification of 2D-landmark protein spots was carried out, and findings are listed in Tables 1 and 2. The tables list the names of identified proteins and their accession number, MS/MS score, isoelectric point, molecular mass, number of peptides, and percentage sequence coverage. A substantial number of the 2D-landmark proteins marked in Fig. 2 (spots 4, 11, 19, 22-29) belong to the class of contractile proteins. Table 1 lists their identity as myosin light chains MLC1f (spots 19 and 29) and MLC2 (spots 26-28), actin (spot 4), tropomyosin (spot 11), troponin TnI (spot 22), and troponin TnT (spots 23-25). In contrast, many of the more neutral-to-acidic protein species belonging to this class of muscle proteins have apparently been removed by differential centrifugation. The list of protein spots marked in Fig. 3 of the subcellular fraction contains only a small number of minor spots with contractile elements, such as actin (spots 16 and 17) and tropomyosin (spots 20 and 21) (Table 2). The high concentration of proteins in the $\mathrm{pH} 8$ range is possibly due to the increased concentration of hydrophobic proteins in the subcellular fraction. Various basic integral proteins poorly label and exhibit an impaired electrophoretic mobility, which might explain the streaky pattern in the $\mathrm{pH} 9$ region of 2D-DIGE gels. For example, our MS-based screening of proteins in the subcellular fraction revealed the presence of the small integral membrane protein 11 (Accession Nos. GI:20270271, NP_620082, MS/MS score 48) at pI 10.01. We have not added this proteomic hit in Table 2 , since this protein was identified by only one peptide. Many of the other 2D-landmark proteins in both gels with crude extracts and the subcellular fraction from skeletal muscle homogenates were identified as components that belong to the class of metabolic enzymes, ion handling proteins, and molecular chaperones.

Comparative proteomic analysis of normal versus dystrophic proteins

The comparative proteomic investigation of normal versus dystrophic $m d x$ muscle, carried out with the contractile-protein-depleted fraction, revealed differential expression patterns for 10 distinct protein spots. A DIGE master gel with the marked proteins that exhibited concentration changes in dystrophin-deficient muscle is presented in Fig. 4. Table 3 lists their mass spectrometric identification. Changed proteins were found to be isoforms of the molecular chaperone Hsp70 (spots 1-3, 6), an unnamed protein BAC34145 (spots 4, 5), ferritin light chain (spot 7), transferrin (spot 8), peptidylprolyl cis-trans isomerase (spot 9), and phosphoglucomutase (spot 10). While the two enzymes were shown to be reduced in abundance, the heat shock proteins and iron-binding proteins were demonstrated to be increased in density (Table 3 ).

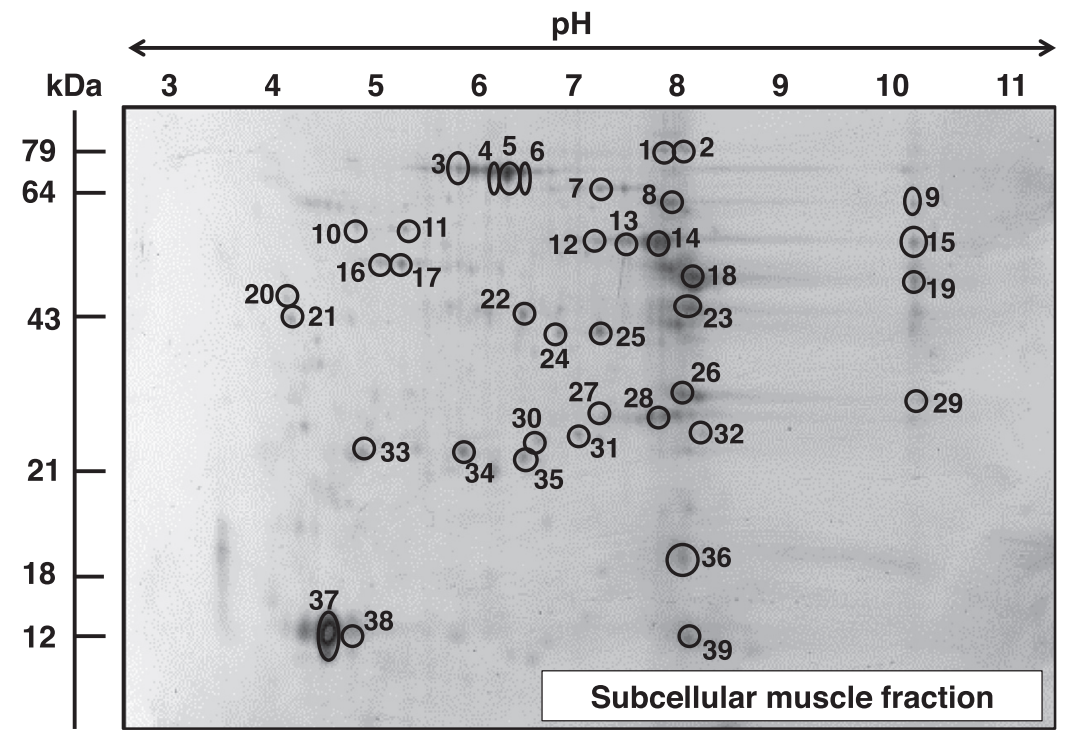

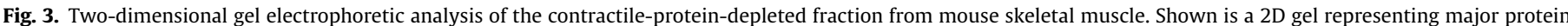

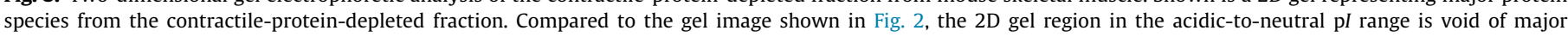

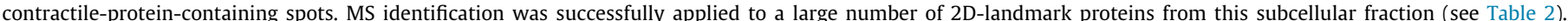

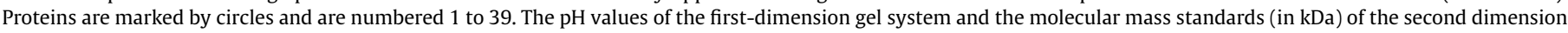
are indicated on the top and on the left, respectively. 
Table 1

List of MS-identified 2D-landmark proteins in the crude tissue extract from skeletal muscle.

\begin{tabular}{|c|c|c|c|c|c|c|c|}
\hline Spot & Protein name & $\begin{array}{l}\text { Accession } \\
\text { No. }\end{array}$ & $\begin{array}{l}\text { MS/MS } \\
\text { score }\end{array}$ & $\begin{array}{l}\text { Isoelectric point } \\
(\mathrm{p} I)\end{array}$ & $\begin{array}{l}\text { Molecular mass } \\
\text { (Da) }\end{array}$ & No. of peptides & $\begin{array}{l}\text { Coverage } \\
(\%)\end{array}$ \\
\hline 1 & ATP synthase, Atp5b protein & АAH37127 & 834 & 5.24 & 56,632 & 34 & 67 \\
\hline 2 & Enolase, $\beta$ & NP_031959 & 1249 & 6.73 & 47,343 & 27 & 63 \\
\hline 3 & Enolase, $\beta$ & NP_031959 & 693 & 6.73 & 47,343 & 28 & 61 \\
\hline 4 & Actin, $\beta$ & CAA27396 & 481 & 5.78 & 39,451 & 15 & 27 \\
\hline 5 & Creatine kinase, M-type & NP_031736 & 911 & 6.58 & 43,250 & 20 & 44 \\
\hline 6 & Creatine kinase, M-type & NP_031736 & 949 & 6.58 & 43,250 & 21 & 46 \\
\hline 7 & Fructose-bisphosphate aldolase A isoform 2 & NP_031464 & 344 & 8.31 & 39,795 & 21 & 57 \\
\hline 8 & Fructose-bisphosphate aldolase $\mathrm{A}$ isoform 2 & NP_031464 & 1063 & 8.31 & 39,795 & 22 & 66 \\
\hline 9 & Calsequestrin, skeletal muscle & AAC63616 & 219 & 3.93 & 45,619 & 12 & 28 \\
\hline 10 & Calsequestrin, skeletal muscle & AAC63616 & 463 & 3.93 & 45,619 & 9 & 25 \\
\hline 11 & Tropomyosin, $\beta$ chain isoform 1 & NP_033442 & 232 & 4.66 & 32,933 & 12 & 30 \\
\hline 12 & Malate dehydrogenase, mitochondrial & NP_032643 & 301 & 8.93 & 36,053 & 11 & 44 \\
\hline 13 & Creatine kinase, M-type & NP_031736 & 551 & 6.58 & 43,250 & 15 & 34 \\
\hline 14 & Glyceraldehyde-3-phosphate dehydrogenase & AAH85315 & 281 & 7.59 & 36,099 & 12 & 46 \\
\hline 15 & Creatine kinase, M-type & NP_031736 & 879 & 6.58 & 43,250 & 19 & 43 \\
\hline 16 & Myozenin-1 & NP_067483 & 406 & 8.57 & 31,438 & 13 & 62 \\
\hline 17 & Carbonic anhydrase, CA3 isoform & NP_031632 & 167 & 6.89 & 29,638 & 15 & 58 \\
\hline 18 & Creatine kinase, M-type & NP_031736 & 267 & 6.58 & 43,250 & 13 & 23 \\
\hline 19 & Myosin light chain MLC1/3 muscle isoform $1 \mathrm{f}$ & NP_067260 & 792 & 4.98 & 20,697 & 17 & 78 \\
\hline 20 & Adenylate kinase isoenzyme AK1 & NP_067490 & 497 & 5.7 & 23,334 & 20 & 74 \\
\hline 21 & Triosephosphate isomerase & AAB48543 & 323 & 5.62 & 22,724 & 12 & 83 \\
\hline 22 & Troponin TnI, fast skeletal muscle & NP_033431 & 191 & 8.65 & 21,518 & 12 & 31 \\
\hline 23 & Troponin TnT, fast muscle isoform & AAB39743 & 237 & 9.01 & 29,358 & 6 & 13 \\
\hline 24 & Troponin TnT, fast muscle isoform & AAL77612 & 351 & 5.08 & 36,537 & 8 & 14 \\
\hline 25 & Troponin TnT, fast muscle isoform & АAB39743 & 378 & 9.01 & 29,358 & 10 & 18 \\
\hline 26 & $\begin{array}{l}\text { Myosin light chain MLC2, skeletal muscle } \\
\text { isoform }\end{array}$ & NP_058034 & 883 & 4.82 & 19,059 & 22 & 92 \\
\hline 27 & $\begin{array}{l}\text { Myosin light chain MLC2, skeletal muscle } \\
\text { isoform }\end{array}$ & NP_058034 & 463 & 4.82 & 19,059 & 21 & 92 \\
\hline 28 & $\begin{array}{l}\text { Myosin light chain MLC2, skeletal muscle } \\
\text { isoform }\end{array}$ & NP_058034 & 162 & 4.82 & 19,059 & 7 & 52 \\
\hline 29 & Myosin light chain MLC1/3, muscle isoform $1 \mathrm{f}$ & NP_067260 & 313 & 4.98 & 20,697 & 11 & 39 \\
\hline 30 & Parvalbumin, $\alpha$ & NP_038673 & 659 & 5.02 & 11,923 & 12 & 71 \\
\hline
\end{tabular}

During an aging study of the dystrophic diaphragm, as previously published for the 8-week to 22-month range [26], we also investigated the 8-week to 12-month range and found a significant increase in heat shock protein Hsp70 cognate (Accession No. AAA37869; MS/MS score 167; pI 5.37; molecular mass 71,025; 5 peptides; $11 \%$ coverage; 3.4 -fold increase in $m d x$ muscle) and ferritin light chain (Accession No. NP_034370; MS/MS score 145; pI 5.66; molecular mass 20,$817 ; 10$ peptides; $65 \%$ coverage; 5.4 -fold increase in $m d x$ muscle).

\section{Comparative immunoblotting of normal versus dystrophic muscle}

Immunoblot analysis was employed to verify the concentration changes in transferrin, Hsp70, and ferritin in normal versus $m d x$ preparations (Fig. 5). Prior to evaluating novel candidates with an altered expression in $m d x$ hindlimb muscle, established marker proteins with no changed abundance, increased abundance, or decreased abundance were blotted. Immunoblots in Fig. 5A-F were carried out with crude tissue extracts to demonstrate altered expression levels on the global muscle protein level. However, immunolabeling of ferritin did not result in a strong enough signal. Therefore this analysis, in combination with the unaltered marker protein parvalbumin, was performed with the contractile-proteindepleted fraction (Fig. 5G and $\mathrm{H}$ ). Immuno-decoration of myosin light chain MLC2, laminin, and parvalbumin showed comparable levels in normal versus $m d x$ preparations (Fig. 5A, B, and G). In contrast, the dystrophin-associated glycoprotein $\beta$-dystroglycan (Fig. 5C) and the extracellular matrix protein collagen (Fig. 5D) displayed drastically altered expression levels in dystrophin-deficient muscle. This agrees with the established reduction of $\beta$-dystroglycan in dystrophinopathy [37] and the considerable increase in collagen in $m d x$ samples [26], as well as an unaltered concentration of various proteins in dystrophic leg muscles [35]. Immunoblotting of the newly established marker candidates of X-linked muscular dystrophy, as identified here by subcellular proteomics, clearly verified their altered concentration in dystrophic muscle. Transferrin, Hsp70, and ferritin light chain exhibited statistically significant increases in $m d x$ hindlimb muscle (Fig. 5E, F, and $\mathrm{H}$ ).

\section{Discussion}

Subproteomic studies have clearly shown that organelle proteomics is highly suitable for the evaluation of global changes in distinct subcellular fractions from skeletal muscles during physiological adaptations or pathological alterations [21]. Although the primary abnormalities causing X-linked muscular dystrophy have been thoroughly established and the corresponding deficiency in the membrane cytoskeletal protein dystrophin is well documented, little is known about the complexity of secondary changes leading to dystrophinopathy. Previous proteomic studies have mostly focused on total tissue extracts and therefore identified mainly abundant muscle-associated proteins, such as components involved in metabolism, excitation-contraction coupling, ion handling, the cellular stress response, and stabilization of the cytoskeleton and extracellular matrix [23-27,30,35]. In contrast, the depletion of the contractile apparatus by differential centrifugation, as shown in this report, enables the comparative proteomic screening of minor protein species in normal versus dystrophic preparations. Minor muscle-associated proteins with a changed concentration in $m d x$ muscle were identified as various isoforms of heat shock protein Hsp70, ferritin light chain, transferrin, and the enzymes peptidylprolyl cis-trans isomerase and phosphoglucomutase. 
Table 2

List of MS-identified 2D-landmark proteins in the contractile protein-depleted fraction from skeletal muscle.

\begin{tabular}{|c|c|c|c|c|c|c|c|}
\hline Spot & Protein name & Accession No. & $\begin{array}{l}\text { MS/MS } \\
\text { score }\end{array}$ & $\begin{array}{l}\text { Isoelectric point } \\
(\mathrm{p} I)\end{array}$ & $\begin{array}{l}\text { Molecular mass } \\
\text { (Da) }\end{array}$ & $\begin{array}{l}\text { No. of } \\
\text { peptides }\end{array}$ & $\begin{array}{l}\text { Coverage } \\
(\%)\end{array}$ \\
\hline 1 & Transferrin & AAL34533 & 41 & 6.92 & 78,832 & 4 & 6 \\
\hline 2 & Phosphofructokinase, muscle & GI:13529638 & 53 & 8.24 & 86,119 & 8 & 10 \\
\hline 3 & Heat shock protein Hsp70, inducible & ABK96811 & 136 & 5.53 & 70,378 & 5 & 11 \\
\hline 4 & Heat shock protein Hsp70, mitochondrial & BAA04493 & 82 & 5.91 & 73,773 & 4 & 7 \\
\hline 5 & Heat shock protein Hsp70, mortalin & AAB28641 & 99 & 5.72 & 73,403 & 4 & 6 \\
\hline 6 & Heat shock protein Hsp70, mitochondrial & BAA04493 & 74 & 5.91 & 73,773 & 2 & 3 \\
\hline 7 & Pgm2 protein, partial & GI:33416468 & 109 & 6.02 & 63,700 & 12 & 24 \\
\hline 8 & Pyruvate kinase, muscle isoform M1 & GI:359807367 & 182 & 6.69 & 58,470 & 11 & 22 \\
\hline 9 & Pyruvate kinase, muscle isoform M1 & GI:359807367 & 148 & 6.69 & 58,470 & 9 & 22 \\
\hline 10 & ATP synthase Atp5b protein & GI:23272966 & 42 & 5.24 & 56,632 & 5 & 12 \\
\hline 11 & Hippocalcin-like protein 1 & GI:407263738 & 44 & 5.54 & 22,459 & 2 & 28 \\
\hline 12 & Enolase, $\beta$ & GI:6679651 & 110 & 6.73 & 47,343 & 4 & 14 \\
\hline 13 & Enolase, $\beta$ & GI:6679651 & 107 & 6.73 & 47,343 & 4 & 13 \\
\hline 14 & Enolase, $\beta$ & GI:6679651 & 316 & 6.73 & 47,343 & 15 & 45 \\
\hline 15 & Enolase, $\beta$ & GI:6679651 & 241 & 6.73 & 47,343 & 12 & 35 \\
\hline 16 & Actin, $\alpha$, skeletal muscle & GI:4501881 & 62 & 5.23 & 42,372 & 7 & 19 \\
\hline 17 & $\beta$-Actin-like protein 2 & GI:30425250 & 44 & 5.3 & 42,325 & 2 & 4 \\
\hline 18 & Creatine kinase, M-type & GI:6671762 & 181 & 6.58 & 43,250 & 6 & 22 \\
\hline 19 & Fructose-bisphosphate aldolase A isoform 2 & GI:6671539 & 71 & 8.31 & 39,795 & 10 & 30 \\
\hline 20 & Tropomyosin, $\beta$ chain & GI:11875203 & 42 & 4.66 & 32,933 & 2 & 9 \\
\hline 21 & Tropomyosin, $\alpha-1$ chain isoform 3 & GI:31560030 & 92 & 4.71 & 32,747 & 9 & 17 \\
\hline 22 & Enolase, $\beta$ & GI:6679651 & 138 & 6.73 & 47,343 & 5 & 16 \\
\hline 23 & Glyceraldehyde-3-phosphate dehydrogenase & GI:6679937 & 83 & 8.44 & 36,077 & 6 & 20 \\
\hline 24 & Malate dehydrogenase, cytosolic & GI:387129 & 108 & 6.16 & 36,628 & 4 & 16 \\
\hline 25 & Malate dehydrogenase, cytosolic & GI:387129 & 113 & 6.16 & 36,628 & 4 & 16 \\
\hline 26 & Phosphoglycerate mutase 2 & GI:9256624 & 93 & 8.65 & 28,980 & 7 & 22 \\
\hline 27 & Triosephosphate isomerase & GI:54855 & 116 & 6.9 & 27,021 & 4 & 20 \\
\hline 28 & Triosephosphate isomerase & GI:54855 & 125 & 6.9 & 27,021 & 8 & 55 \\
\hline 29 & Phosphoglycerate mutase 2 & GI:9256624 & 60 & 8.65 & 28,980 & 4 & 17 \\
\hline 30 & DJ-1 protein & GI:55741460 & 42 & 6.32 & 20,236 & 3 & 12 \\
\hline 31 & $\begin{array}{l}\text { Thioredoxin-dependent peroxide reductase, } \\
\text { mitochondrial }\end{array}$ & GI:6680690 & 57 & 7.15 & 28,337 & 4 & 16 \\
\hline 32 & Manganese superoxide dismutase & GI:53450 & 36 & 8.8 & 24,894 & 2 & 3 \\
\hline 33 & Phosphatidylethanolamine binding protein & GI:1517864 & 93 & 5.19 & 21,018 & 3 & 18 \\
\hline 34 & Adenylate kinase, isoenzyme AK1 & GI:10946936 & 87 & 5.7 & 23,330 & 5 & 33 \\
\hline 35 & Ferritin light chain 1 & GI:120524 & 81 & 5.66 & 20,847 & 4 & 32 \\
\hline 36 & Peptidylprolyl cis-trans isomerase A & NP_032933 & 89 & 7.74 & 18,134 & 4 & 35 \\
\hline 37 & Parvalbumin & GI:53819 & 80 & 5.02 & 11,937 & 3 & 26 \\
\hline 38 & Parvalbumin & GI:53819 & 136 & 5.02 & 11,937 & 6 & 57 \\
\hline 39 & Hemoglobin $\beta$ & GI:229301 & 98 & 7.26 & 15,767 & 5 & 40 \\
\hline
\end{tabular}

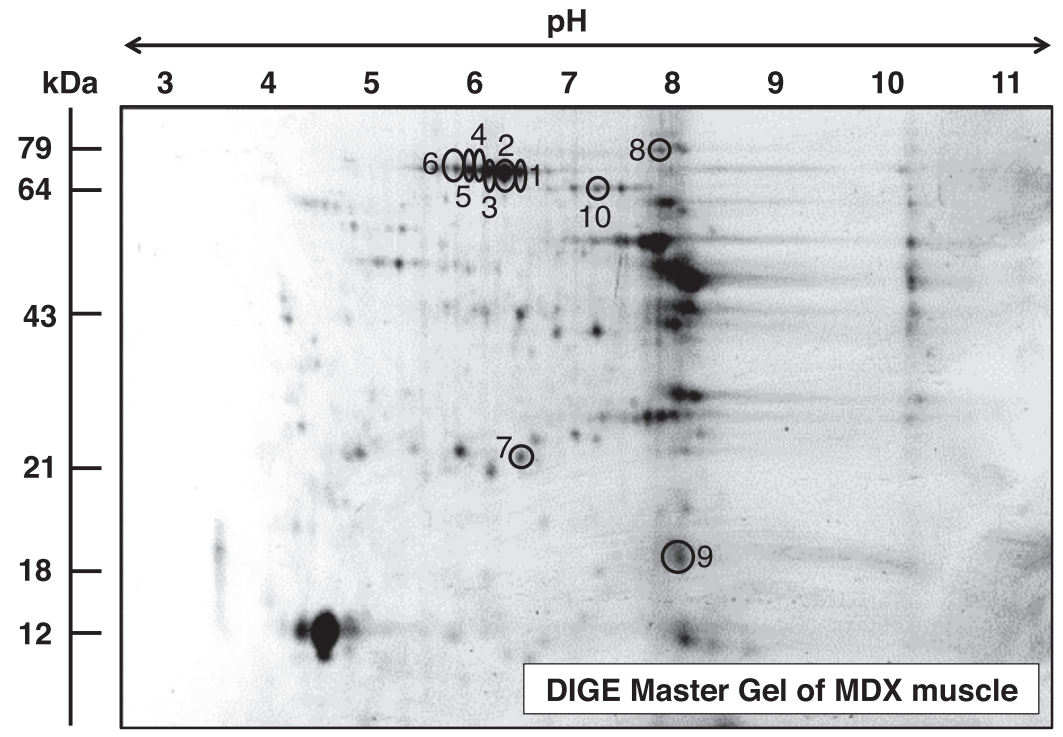

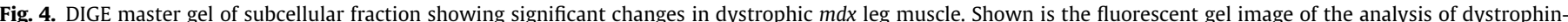

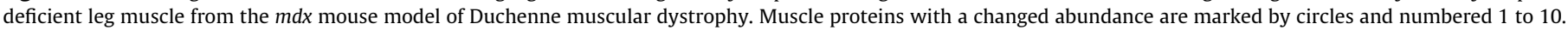

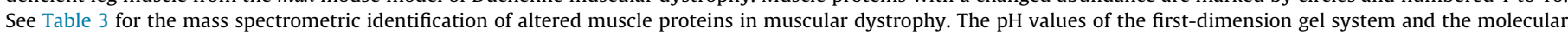
mass standards (in $\mathrm{kDa}$ ) of the second dimension are indicated on the top and on the left, respectively. 
Table 3

Changed proteins in subcellular fraction from $m d x$ leg muscle as determined by fluorescent 2D-DIGE analysis.

\begin{tabular}{|c|c|c|c|c|c|c|c|c|}
\hline Spot & Protein name & $\begin{array}{l}\text { Accession } \\
\text { No. }\end{array}$ & $\begin{array}{l}\text { MS/MS } \\
\text { score }\end{array}$ & $\begin{array}{l}\text { Isoelectric point } \\
(\mathrm{p} I)\end{array}$ & $\begin{array}{l}\text { Molecular mass } \\
\text { (Da) }\end{array}$ & $\begin{array}{l}\text { No. of } \\
\text { peptides }\end{array}$ & $\begin{array}{l}\text { Coverage } \\
(\%)\end{array}$ & $\begin{array}{l}\text { Fold } \\
\text { change }\end{array}$ \\
\hline 1 & $\begin{array}{l}\text { Heat shock protein Hsp70, } \\
\text { mitochondrial }\end{array}$ & BAA04493 & 74 & 5.91 & 73,773 & 2 & 3 & 1.9 \\
\hline 2 & Heat shock protein Hsp70, mortalin & AАB28641 & 99 & 5.72 & 73,403 & 4 & 6 & 1.9 \\
\hline 3 & $\begin{array}{l}\text { Heat shock protein Hsp70, } \\
\text { mitochondrial }\end{array}$ & BAA04493 & 82 & 5.91 & 73,773 & 4 & 7 & 1.9 \\
\hline 4 & Unnamed protein product & BAC34145 & 238 & 5.75 & 70,730 & 11 & 22 & 1.8 \\
\hline 5 & Unnamed protein product & BAC34145 & 305 & 5.75 & 70,730 & 9 & 18 & 1.8 \\
\hline 6 & Heat shock protein Hsp70, inducible & ABK96811 & 136 & 5.53 & 70,378 & 5 & 11 & 1.7 \\
\hline 7 & Ferritin light chain 1 & GI:120524 & 81 & 5.66 & 20,847 & 4 & 32 & 1.6 \\
\hline 8 & Transferrin & AAL34533 & 41 & 6.92 & 78,832 & 4 & 6 & 1.6 \\
\hline 9 & Peptidylprolyl cis-trans isomerase A & NP_032933 & 89 & 7.74 & 18,134 & 4 & 35 & -1.4 \\
\hline 10 & Pgm2 protein, partial & GI:33416468 & 109 & 6.02 & 63,700 & 12 & 24 & -1.7 \\
\hline
\end{tabular}

A Myosin MLC2

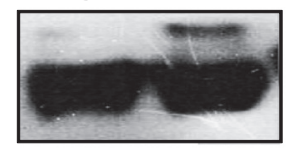

12

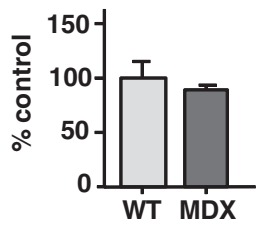

E Transferrin

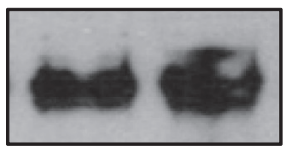

12

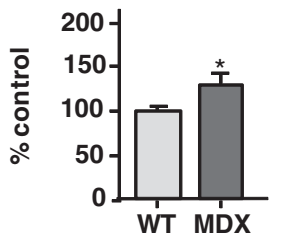

B Laminin

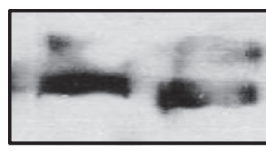

12

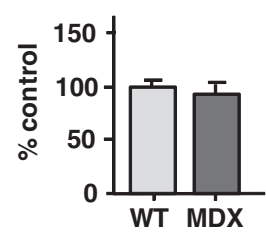

F Hsp70

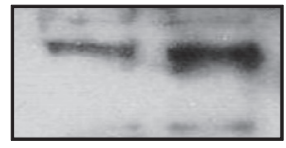

1

2

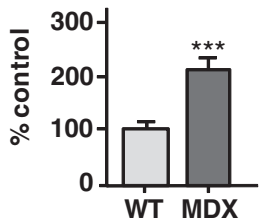

C $\beta$-Dystroglycan
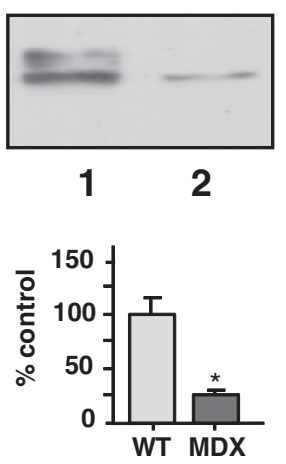

G Parvalbumin

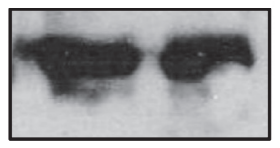

34

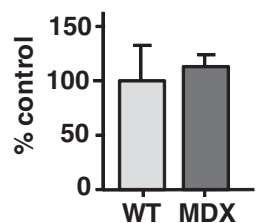

D Collagen

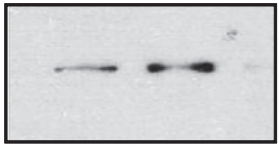

12

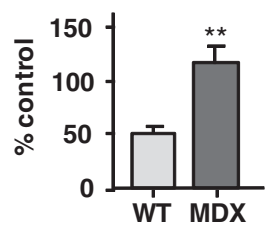

H Ferritin LC
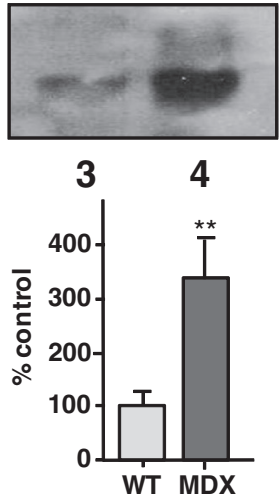

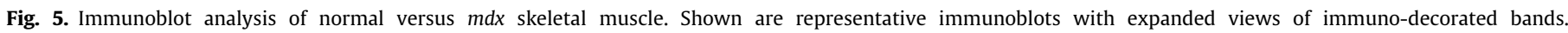

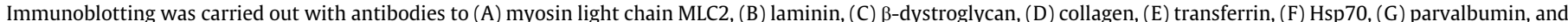

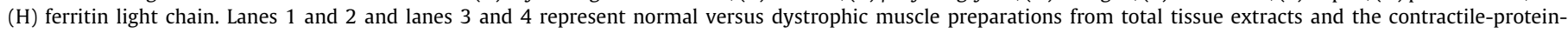

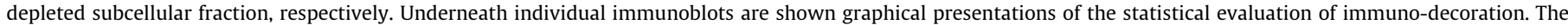

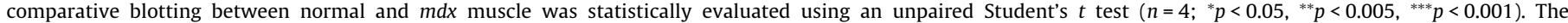
concentrations of $\beta$-dystroglycan, collagen, transferrin, Hsp70, and ferritin light chain were significantly different between normal and dystrophic $m d x$ leg muscle.

Transferrin [38] and ferritin [39] are crucial iron-transporting proteins and crucial elements of iron metabolism [40]. Increased levels of transferrin and ferritin in dystrophic muscle agree with recent findings from the proteomic analysis of the aged $m d x$ diaphragm [26] and the aged $m d x$ heart [41]. Deficiency in dystrophin appears to disturb iron homeostasis, and the increased concentration of iron-binding-proteins and transporters might reflect a compensatory mechanism to prevent a harmful iron overload in muscle tissues. Increased levels of molecular chaperones are indicative of enhanced cellular stress in dystrophic muscle tissue. Heat shock protein Hsp70 is a major molecular chaperone and exists as several different isoforms [42]. Hsp70 isoforms play major roles in skeletal muscle stress triggered by injury, excessive exercise, reperfusion-induced ischemia, oxidative conditions, and neuromuscular disorders [43]. Chaperone regulation was shown to be crucial for protecting stressed muscle from damage [44]. Thus, the apparent upregulation of mitochondrial Hsp70 isoforms can be interpreted as a countermeasure to protect dystrophic fibers from excessive oxidative stress and agrees with previous findings on increased levels of the small heat shock protein cvHsp in dystrophin-deficient skeletal muscle [45]. In addition to Hsp70, two protein spots with similar molecular masses and slightly different 
isoelectric points showed an increased concentration. These protein spots correspond to an unnamed protein (BAC34145 protein, GI:26340966) with unknown function.

The reduction in the enzymes peptidylprolyl isomerase and phosphoglucomutase indicates impaired protein-folding processes and abnormal glycogen utilization in $m d x$ muscle, respectively. Peptidylprolyl isomerase facilitates the accelerated folding of proteins. In oligopeptides, this enzyme catalyzes the cis-trans isomerization of proline imidic peptide bonds [46]. Thus, its reduced presence might lower the ability of dystrophic muscles to properly refold certain classes of muscle proteins. Phosphoglucomutase mediates the interconversion of glucose 1-phosphate and glucose 6-phosphate during glycogenolysis and glycogenesis, making it a critical protein of glycogen and glucose metabolism in muscle [47]. Decreased levels of this enzyme point toward impaired glucose utilization in dystrophic muscle fibers.

Hence, the systematic depletion of contractile proteins from muscle preparations prior to gel electrophoretic protein separation has been shown to provide better access to minor protein species from dystrophic muscle. This report demonstrates that the application of gel-based organelle proteomics can overcome certain technical limitations of whole-tissue proteomics by reducing sample complexity via prefractionation steps prior to mass spectrometric analysis. Since skeletal muscle tissues are characterized by a particularly diverse range of minor protein isoforms and a large dynamic range of protein expression patterns, the application of organelle proteomics for studying adapting or pathological muscles promises a more comprehensive coverage of the skeletal muscle proteome.

\section{Acknowledgments}

Research was supported by project grants from Muscular Dystrophy Ireland and Duchenne Ireland, as well as equipment grants from the Irish Health Research Board and the Higher Education Authority.

\section{References}

[1] I.A. Brewis, P. Brennan, Proteomics technologies for the global identification and quantification of proteins, Adv. Protein Chem. Struct. Biol. 80 (2010) 1-44.

[2] B.T. Chait, Mass spectrometry in the postgenomic era, Annu. Rev. Biochem. 80 (2011) 239-246.

[3] T.E. Angel, U.K. Aryal, S.M. Hengel, E.S. Baker, R.T. Kelly, E.W. Robinson, R.D. Smith, Mass spectrometry-based proteomics: existing capabilities and future directions, Chem. Soc. Rev. 41 (2012) 3912-3928.

[4] A. Bensimon, A.J. Heck, R. Aebersold, Mass spectrometry-based proteomics and network biology, Annu. Rev. Biochem. 81 (2012) 379-405.

[5] D. Calligaris, C. Villard, D. Lafitte, Advances in top-down proteomics for disease biomarker discovery, J. Proteomics 74 (2011) 920-934.

[6] K. Ohlendieck, Proteomic identification of biomarkers of skeletal muscle disorders, Biomarkers Med. 7 (2013) 169-186.

[7] T. Rabilloud, M. Chevallet, S. Luche, C. Lelong, Two-dimensional gel electrophoresis in proteomics: past, present and future, J. Proteomics 73 (2010) 2064-2077.

[8] V.J. Gauci, E.P. Wright, J.R. Coorssen, Quantitative proteomics: assessing the spectrum of in-gel protein detection methods, J. Chem. Biol. 4 (2011) 3-29.

[9] P.W. Reed, A. Densmore, R.J. Bloch, Optimization of large gel 2D electrophoresis for proteomic studies of skeletal muscle, Electrophoresis 33 (2012) 1263 1270.

[10] F. Xie, T. Liu, W.J. Qian, V.A. Petyuk, R.D. Smith, Liquid chromatography-mass spectrometry-based quantitative proteomics, J. Biol. Chem. 286 (2011) $25443-$ 25449.

[11] X. Han, A. Aslanian, J.R. Yates 3rd, Mass spectrometry for proteomics, Curr Opin. Chem. Biol. 12 (2008) 483-490.

[12] A.F. Altelaar, A.J. Heck, Trends in ultrasensitive proteomics, Curr. Opin. Chem. Biol. 16 (2012) 206-213.

[13] A.F. Altelaar, J. Munoz, A.J. Heck, Next-generation proteomics: towards an integrative view of proteome dynamics, Nat. Rev. Genet. 14 (2013) 35-48.

[14] K. Ohlendieck, Proteomics of skeletal muscle differentiation, neuromuscular disorders and fiber aging, Expert Rev. Proteomics 7 (2010) 283-296.

[15] C. Gelfi, M. Vasso, P. Cerretelli, Diversity of human skeletal muscle in health and disease: contribution of proteomics, J. Proteomics 74 (2011) 774-795.
[16] A. Holland, K. Ohlendieck, Proteomic profiling of the contractile apparatus from skeletal muscle, Expert Rev. Proteomics 10 (2013) 239-257.

[17] J.R. Yates 3rd, A. Gilchrist, K.E. Howell, J.J. Bergeron, Proteomics of organelles and large cellular structures, Nat. Rev. Mol. Cell Biol. 6 (2005) 702-714.

[18] D.J. Gauthier, C. Lazure, Complementary methods to assist subcellular fractionation in organellar proteomics, Expert Rev. Proteomics 5 (2008) 603617.

[19] U. Michelsen, J. von Hagen, Isolation of subcellular organelles and structures, Methods Enzymol. 463 (2009) 305-328.

[20] P. Souda, C.M. Ryan, W.A. Cramer, J. Whitelegge, Profiling of integral membrane proteins and their post translational modifications using highresolution mass spectrometry, Methods 55 (2011) 330-336.

[21] K. Ohlendieck, Organelle proteomics in skeletal muscle biology, J. Integr. Omics 2 (2012) 27-38.

[22] A. Emery, F. Muntoni, Duchenne Muscular Dystrophy, 3rd ed., Oxford Univ. Press, Oxford, 2003.

[23] C. Lewis, S. Carberry, K. Ohlendieck, Proteomic profiling of X-linked muscular dystrophy, J. Muscle Res. Cell. Motil. 30 (2009) 267-279.

[24] L. Guevel, J.R. Lavoie, C. Perez-Iratxeta, K. Rouger, L. Dubreil, M. Feron, S. Talon, M. Brand, L.A. Megeney, Quantitative proteomic analysis of dystrophic dog muscle, J. Proteome Res. 10 (2011) 2465-2478.

[25] D. Gardan-Salmon, J.M. Dixon, S.M. Lonergan, J.T. Selsby, Proteomic assessment of the acute phase of dystrophin deficiency in mdx mice, Eur. J. Appl. Physiol. 111 (2011) 2763-2773.

[26] S. Carberry, M. Zweyer, D. Swandulla, K. Ohlendieck, Proteomics reveals drastic increase of extracellular matrix proteins collagen and dermatopontin in the aged mdx diaphragm model of Duchenne muscular dystrophy, Int. J. Mol. Med. 30 (2012) 229-234.

[27] S. Rayavarapu, W. Coley, E. Cakir, V. Jahnke, S. Takeda, Y. Aoki, H. GrodishDressman, J.K. Jaiswal, E.P. Hoffman, K.J. Brown, Y. Hathout, K. Nagaraju, Identification of disease specific pathways using in vivo SILAC proteomics in dystrophin deficient mdx mouse, Mol. Cell. Proteomics 12 (2013) 1061-1073.

[28] K. Ohlendieck, J.M. Ervasti, J.B. Snook, K.P. Campbell, Dystrophin-glycoprotein complex is highly enriched in isolated skeletal muscle sarcolemma, J. Cell Biol. 112 (1991) 135-148.

[29] J. Gannon, P. Doran, A. Kirwan, K. Ohlendieck, Drastic increase of myosin light chain MLC-2 in senescent skeletal muscle indicates fast-to-slow fibre transition in sarcopenia of old age, Eur. J. Cell Biol. 88 (2009) 685-700.

[30] S. Carberry, M. Zweyer, D. Swandulla, K. Ohlendieck, Profiling of age-related changes in the tibialis anterior muscle proteome of the mdx mouse model of dystrophinopathy, J. Biomed. Biotechnol. 2012 (2012) 691641.

[31] K. O'Connell, K. Ohlendieck, Proteomic DIGE analysis of the mitochondriaenriched fraction from aged rat skeletal muscle, Proteomics 9 (2009) 55095524.

[32] C. Aude-Garcia, V. Collin-Faure, S. Luche, T. Rabilloud, Improvements and simplifications in in-gel fluorescent detection of proteins using ruthenium II tris-(bathophenanthroline disulfonate): the poor man's fluorescent detection method, Proteomics 11 (2011) 324-328.

[33] S. Carberry, K. Ohlendieck, Gel electrophoresis-based proteomics of senescent tissues, Methods Mol. Biol. 1048 (2013) 229-246.

[34] C. Lewis, P. Doran, K. Ohlendieck, Proteomic analysis of dystrophic muscle, Methods Mol. Biol. 798 (2012) 357-369.

[35] S. Carberry, H. Brinkmeier, Y. Zhang, K. Claudia, K. Ohlendieck, Comparative proteomic profiling of soleus, extensor digitorum longus, flexor digitorum brevis and interosseus muscle from the mdx mouse model of Duchenne muscular dystrophy, Int. J. Mol. Med. 32 (2013) 544-556.

[36] C. Lewis, K. Ohlendieck, Mass spectrometric identification of dystrophin isoform Dp427 by on-membrane digestion of sarcolemma from skeletal muscle, Anal. Biochem. 404 (2010) 197-203.

[37] K. Ohlendieck, K.P. Campbell, Dystrophin-associated proteins are greatly reduced in skeletal muscle from mdx mice, J. Cell Biol. 115 (1991) 1685-1694.

[38] D. Szőke, M. Panteghini, Diagnostic value of transferrin, Clin. Chim. Acta 413 (2012) 1184-1189.

[39] R.R. Crichton, J.P. Declercq, X-ray structures of ferritins and related proteins, Biochim. Biophys. Acta 2010 (1800) 706-718.

[40] J. Wang, K. Pantopoulos, Regulation of cellular iron metabolism, Biochem. J. 434 (2011) 365-381.

[41] A. Holland, P. Dowling, M. Zweyer, D. Swandulla, M. Henry, M. Clynes, K. Ohlendieck, Proteomic profiling of cardiomyopathic tissue from the aged mdx model of Duchenne muscular dystrophy reveals a drastic decrease in laminin, nidogen and annexin, Proteomics 13 (2013) 2312-2323.

[42] J.C. Young, Mechanisms of the Hsp70 chaperone system, Biochem. Cell Biol. 88 (2010) 291-300.

[43] Y. Liu, L. Gampert, K. Nething, J.M. Steinacker, Response and function of skeletal muscle heat shock protein 70. Front. Biosci. 11 (2006) 2802-2827.

[44] A.A. Maglara, A. Vasilaki, M.J. Jackson, A. McArdle, Damage to developing mouse skeletal muscle myotubes in culture: protective effect of heat shock proteins, J. Physiol. 548 (2003) 837-846.

[45] P. Doran, G. Martin, P. Dowling, H. Jockusch, K. Ohlendieck, Proteome analysis of the dystrophin-deficient MDX diaphragm reveals a drastic increase in the heat shock protein cvHSP, Proteomics 6 (2006) 4610-4621.

[46] H.R. Quintá, N.M. Galigniana, A.G. Erlejman, M. Lagadari, G. Piwien-Pilipuk, M.D. Galigniana, Management of cytoskeleton architecture by molecular chaperones and immunophilins, Cell. Signalling 23 (2011) 1907-1920.

[47] K. Ohlendieck, Proteomics of skeletal muscle glycolysis, Biochim. Biophys. Acta 2010 (1804) 2089-2101. 